\title{
S ЧЕЛОВЕК И ГРАЖДАНИН
}

Кананыкина E.C.

\section{РЕЛИГИОЗНЫЙ И РАСОВЫЙ ПРИЗНАК В АМЕРИКАНСКИХ СУДЕБНЫХ ПРЕЦЕДЕНТАХ}

\begin{abstract}
Аннотация: Традищионных религий в США официально зарегистрировано более 23-х. Некоторые из них, например, непосредственно контролируют систему приходских школ, но введение любой из них в публичные школы ли усилило бы и без того острые конфликты в них. Поэтому, считается, что «общегражданская» религия, приверженцами которой должны быть представители любого вероисповедания, представляет собой наиболее адаптированный вариант привития школьникам «хоротего тона» общения с Богом.
\end{abstract}

Review: There are over 23 officially registered traditional religions in the USA. Some of them directly control the system of parish school, but if any of these were to be introduced into the public schools, the existing conflicts would escalate. Therefore, it is considered that the general civil religion, which representatives of any religious denomination should follow, is a basically adapted version of the "good courtesy" in communications with God for the schoolchildren.

Ключевые слова: Политология, право, религия, секуляризачия, система, прецедент, законодательство, Америка, суд, расы

Keywords: political science, religion, secularization, system, precedent, legislation, America, court, races.

\section{О секуляризации...}

A мериканская религиозность исторически проявляется в двух формах - традиционной и «общегражданской». Последнюю из них интенсивно пытаются навязать школьникам ${ }^{1}$.

Традиционных религий в США официально зарегистрировано более $23-\mathrm{x}$. Некоторые из них, например, непосредственно контролируют систему приходских школ, но введение любой из них в публичные школы ли усилило бы и без того острые конфликты в них. Поэтому, считается, что «общегражданская» религия, приверженцами которой должны быть представители любого вероисповедания, представляет собой наиболее адаптированный вариант привития школьникам «хорошего тона» общения с Богом.

${ }^{1}$ Jeynes W. School Choice // Cambridge Journal of education. 2001. № 4. - P. 232-235.
Согласно положениям этой религии Америка единственная покровительствуемая Богом страна, «последний бастион свободы на Земле». По сути говоря, это религия являет собой квинтэссенцию американского образа жизни, освященного сверхъестественным авторитетом.

В соответствии с мнением первых руководящих лиц государства и поддерживающих их консервативных политиков, «дети должны...проникнуться сознанием богоизбранности Америки, ее миссии сохранения «христианской цивилизации». Другими словами, они должны усвоить начатки «общегражданской религии», делающей предметом поклонения не потустороннего Бога, а свою «лучшую в мире страну». Лозунг этой религии, интенсивно вводимый в школы многих штатов, - «американизм против коммунизма, добро против зла».

До революции 1766 г. влияние различных религиозных объединений на систему образования порождало пестроту в способах, средствах и характере 


\section{Политика и общество 8 (104) • 2013}

обучения, акцентировало ее внимания на сугубо религиозной проблематике.

Система публичных школ, созданная с целью унификации системы образования, ослабления влияния церкви, стала результатом революционных преобразований США в конце XVIII в. Согласно первой поправке к Конституции США от 1801 г., церковь в Америке отделена от государства. А это значит, что подведомственная государственному Департаменту образования, властям штата и местным школьным округам система публичных школ должна быть свободной от религиозного влияния.

«Секуляризация» американских публичных школ усилилась с принятием штатами Мичиган в 1835 2. и Висконсин в 1848 2. законов, запрещающих финансовую поддержку религиозным обществам. Эти законы впоследствии были приняты всеми штатами. Сегодня теоретиками образовательного процесса утверждена максима: «Гражданственность должна основываться на морали, а мораль на религии»².

После окончания Второй мировой войны вопрос о статусе религии в публичных школах часто становился предметом судебных разбирательств, в результате чего складывалась парадоксальная ситуация: с одной стороны, Верховный Суд все чаще выносил решения о запрещении практиковать тот или иной вид религиозности в публичных школах, с другой - правящие круги США стремились сохранить религию в качестве «моральной узды» для учеников, и это находило все новые формы проявления.

Так, по решению Верховного Суда 1943 2. (West Virginia State Board of Education v. Barnette 319 U.S. 624) были признаны неконституционными иеремонии салюта и клятвы на верность государственному флагу в качестве подтверждения принадлежности к американской нации, как противоречащие религиозной свободе. Прецедентом послужило изгнание из публичных школ детей сектантов Свидетелей Иеговы, отказавшихся «поклоняться идолу» (т.е. государственному шлагу). Однако продолжало широко практиковаться добровольное участие в патриотических церемониях, а флаг до сих пор можно увидеть в любой из американских школ. Клятва на верность звучит перед открытием занятий в школе, в торжественных случаях, хотя и не признается обязательной.

${ }^{2}$ Time. - 1984. February 6. - P. 34-39.
Важным фактом в длительной истории решений Верховного суда было запрещение обязательных молитв в публичных школах.

Когда в 1951 г. Советом школьных регентов штата Нью-Йорк было предложено ввести молитву «Всемогущий боже, мы признаем свою зависимость от тебя, мы просим твоего благословения на нас, наших родителей, наших учителей и нашу страну», родители учеников одной из школ выразили сомнение в уместности такой молитвы и ее совместимости с первой поправкой к Конституции.

Решением Верховного суда 1952 г. учащимся публичных школ разрешили посещать религиозные службы в учебное время, хотя они не должны были устраиваться в школьных помещениях.

Среди самых нашумевших судебных дел по проблеме сегрегации и отстаивания прав по религиозному признаку II пол. XX столетия можно назвать дело McCollum v. Board of Education, 333 U.S. 20319532. об установления школьными округами штата Иллинойса обязательности посещения религиозных уроков лицам принадлежащим к иным конфессиям, чем католическая; дело Zorach v. Clauson, 343 U.S. 306 1958 г. по решению которого учащиеся могли не посещать определенные предметы, заменяя их религиозными богослужениями, посещением религиозных центров при условии разрешения подобного родителями, а в случае отсутствия такового учащиеся были обязаны находится в здании школы, даже если занятий в данное время не было; по делу Murray v. Curtlett № 119. 374 U.S. 2031960 г. обязал всех учащихся начинать занятия с прочтения Библии, отказавшиеся из них не допускались к занятиям; прецедент дела School District of Abington Township v. Schempp № 142. 1962 2. Верховный суд признал несостоятельными попытки введения общенациональной религиозности для образовательных целей и запретил молитвы в публичных школах. Дополнением к этому было решение 1963 г. о запрете ежедневного чтения отрывков из библии перед занятиями.

В последующие годы влияние религии на систему образования заметно усиливается. Сложившаяся ситуация характеризуется тенденцией к отмене законодательства о безрелигиозном характере публичного образования.

Особую активность веяния новой тенденции проявило Моральное большинство, консервативная религиозно-политическая организация, нацеленная на возрождение традиционных ценностей американиз- 
ма и христианства, противопоставляя их «безбожному коммунизму».

Название «Моральное большинство» имеет целью внушить приверженцам и противникам организации представление о ее, якобы, массовом характере. Власти многих штатов, руководствуясь консервативными политическими установками, развернули кампанию за отмену запрета на молитвы в публичных школах ${ }^{3}$.

В 1983-85 гг. от имени президентской администрации Р. Рейгана была предпринята попытка отменить решение Верховного суда 1963 г. о запрещении молитв в публичных школах.

Одним из инициаторов отмены решения Верховного суда 1962 г. выступил сенатор-республиканец из Северной Каролины, лидер американских консерваторов Дж. Хелмс. Он был поддержан Моральным большинством, многими протестантами, православными и частью католиков, а также Президентом Р. Рейганом и его ближайшим окружением.

Соласно Хелмсу, признание и прославление Христа - необходимая часть национального наследия, а ежедневная молитва - важнейшее условие образовательного и воспитательного процесса; право же вводить молитвы принадлежит родителям и учителям, а не федеральным судьям.

«В Америке со времени отцов-основателей говорилось не о свободе от религии, а о свободе религии»,- заявил он. Поэтому следует отменить решение Верховного суда 1963 г. юридически, тем более что фактически во многих школах уже проводятся моления, а административные органы многих штатов признают частично их правомочность.

Многие протестантские церковники США выступают против повторного введения молитв в школы, видя в этом сращивание государства и религии. Стремясь сохранить свое влияние на демократически ориентированные слои населения США, они придерживаются принципов буржуазного индивидуализма в вопросах религии, согласно которым каждый добровольно выбирает себе веру. Например, отрицательно относящийся к введению молитв публичные школы либерально настроенные священник Ч. Бергстром в 1982 г. заявил, что поскольку основа религии - личная приверженность Богу, то никого нельзя принудить молиться, так как это неприемлемо с позиций социальной справедливости. К пересмотру решения Верховно-

\footnotetext{
${ }^{3}$ Churches and State. - 1983. № 5. - P. 16.
}

го суда, по его мнению, побуждают не искренние чувства верующих, а правые политики и консервативные идеологи. «Шестилетнему ребенку трудно, оказавшись в группе молящихся, не подчиниться ей, а подобное подчинение несовместимо с истинной религиозностью», - пишет он ${ }^{4}$.

Решительные сторонники введения молитв в школе, не останавливающиеся перед нарушением «священной» Конституции США или обходя законы, действуют и по сей день весьма эффективно. Так, власти штата Кентукки потребовали введения таблички с 10 заповедями во всех школах страны для «поднятия морального духа народа».

Чтобы обойти первую поправку к Конституции, запрещающую издание законов, устанавливающих какую-либо религию, равно как и решение Верховного суда от 1963 г., адвокат назвал 10 заповедей «фундаментальным легальным кодексом западной цивилизации и Общим законом Соединенных Штатов». Верховный Суд не принял такого толкования, сочтя их все же «религиозным текстом» ${ }^{5}$.

В середине десятилетия прецедент по делу Wallace v. Jaffree 472 U.S. 381982 2. заменил запрещенную Конституцией США молитву в начале учебного дня минутой молчаливо обращения к Богу - «момент тишины» ${ }^{6}$.

При обращении в Верховный суд штата Алабамы было принято решение одобрить данную практику в школах, поскольку власти штата Алабама имеют право устанавливать государственную религию, действующую на территории штата. Верховный суд США аннулировал данное решение, как и массу других ${ }^{7}$.

Что касается указанной формы обхода запрета на молитвы в публичных школах, так называемого, момента тишинь, во время которого учащиеся должны молчаливо молиться, обращаясь к Богу, то он, по сути, дополняет клятву верности государственному флагу США, открывающие занятия во многих публичных школах.

В начале 1983 г. более 12 штатов ввели такой «момент» законодательно; к 1984 г. их число достигло уже 23, но ни первая, ни вторая попытки закрепить его решениями Верховного суда не увенчались успехом.

\footnotetext{
${ }^{4}$ U. S. New and World Report. - 1982. November 15. - P. 4-5.

5 Time. - 1980. December. - P, 23-26.

${ }^{6}$ Олещук Ю.Ф. Эволюция социальной политики США. - М., 1987. - Сю 34-40.

${ }^{7}$ http:// caselaw.lp.findlaw.com/scripts/getcase.com.
} 


\section{О сегрегации...}

В 1960-е гг. Верховный суд США и суды штатов приняли ряд решений по борьбе с расовой дискриминацией в области образования, но все они в основном касались совместной перевозки белых и черных учащихся на автобусах.

По признаку нацчиональной принадлежности были созданы прецеденты по делам Everson v. Board of Education 330 U.S. 1. 1947 2. о неправомерном установлении администрацией школьного округа правил и условий раздельной транспортировки белых и цветных детей и Board of Education v. Allen 392 U.S. 236. 1968 2., в соответствии с которым, школьная администрация требовала от «небелых» обучающихся приносить в школу свои учебники, в тоже время детям, принадлежащим к белой расе учебники выдавались.

В 1970-х гг. законодательные и судебные органы приняли ряд решений, направленных на ограничение и запрещение транспортной перевозки школьников ${ }^{8}$.

Сегодня совершенно немыслимыми кажутся сведения о том, что к началу 1990-х гг. еще в 17-ти южных штатах и округе Колумбия не разрешалось совместное обучение белых и цветных людей. По Закону, изданному в Миссисипи в 1955 г. и продолжающему действовать в 1988 г., европейцы, посещающие школу для негров подвергались штрафу или тюремному заключению.

К Конституичии итата Луизиана принята поправка об обязательном раздельном обучении черных и белых, не по причине различий в расе, а для содействия улучшению состояния здоровья, морального покоя и порядка ${ }^{9}$.

Изложим суть нескольких самых громких процессов направленных на десегрегацию обучения.

По сути дела Braun v. Board of education of Toreca et.al. 347 U.S. 483. 74S. Ct.686. 98 L. Ed. 873 1954 2. Председатель Верховного суда Уоренс изложил следующее:

«Эти дела поступили к нам из штата Канзас, Южная Каролина, Виргиния, Делавер. Они основывают-

\footnotetext{
${ }^{8}$ США: государство и социальная политика. К анализу консервативных тенденций 1980-х гг. / Под ред. С.М. Плеханова. - М.: Изд-во «Наука», 1988. - 186 с.

${ }^{9}$ Wright L. Physical education and moral education, Journal of Philosophy of Education, 21, Moral Character and Civic Education in the Elementary School. - New York, Teachers College Press, 1997. - P. 21-24.
}

ся на различных фактах, также как в их основе лежат различные местные условия. Однако общая юридическая проблема делает возможным их совместное рассмотрение в свободном решении.

В каждом из этих дел несовершеннолетние лица, принадлежащие к нергитянской расе, с помощью своих юридических представителей стремятся заручиться помощью судов с тем, чтобы быть принятыли в государственные школь своих общин на несегрегаџионной основе. В каждом случае им было отказано в доступе в школу, посещаемую белыми детьми, в соответствии с законами, требующими или допускающими раздельное обучение по расовым признакам. Как утверждается, такая сегрегация лишала истцов равной защиты законом в соответствии с Поправкой XIV.

В каждом деле, за исключением дела в штате Делавер, федеральный окружной суд в составе трех судей отказался удовлетворить иски по основным требованиям доктрины «разных, но равных» возможностей, провозглашенные этим судом в деле Plessy v. Ferguson 163 VS 537. В соответствии с этой новой доктриной равенство предоставляется тогда, когда расы обеспечиваются в основном одинаковыми помещениями для обучения, даже если эти помещения раздельные.

В случае Делавера Верховный Суд штата придерживался именно этой доктрины. Вместе с тем, он вынес решение о том, что истец должен быть принят в школы для белых, так как последние были лучше негритянских школ ${ }^{10}$.

Истиь утверждают, что сегрегированные государственные школь не являются «равными» и вследствие этого лишены зашиты законов.

Учитывая несомненную значимость поднятой проблемы, Суд принял дело на рассмотрение».

Контраргументы комплексного дела Braun v. Board of education of Toreca et. al. были в основном посвящены обстоятельствам, сопровождавшим принятие Поправки XIV в 1868 г. Конгрессе и ее ратификации штатами, на существовавшей в то время практике расовой сегрегации и взглядах сторонников и противников поправки.

Суд остановился на том, что невозможно сколько-нибудь определенно установить, что именно име-

\footnotetext{
${ }^{10}$ Фридмен Л. Введение в американское право / Пер с англ. / Под ред. М. Калонтаровой. - М.: Изд-во «Прогресс», «Универе», 1993. - $286 \mathrm{c}$.
} 
ли в виду другие лица в Конгрессе или законодательных органах штатов, но объективно, несомненно, что самые ярые сторонники послевоенных поправок ставили себе цель устранить все юридические различия между всеми лицами, «родившимися или натурализованными в Соединенных Штатах». Столь же несомненно, что их противники выступали против духа и буквы поправок и ставили себе цель ограничить последствия их применения на практике.

Еще одной причиной, объясняющей неубедительный характер истории с поправкой в отношении сегрегированных школ, является состояние государственного образования в то время. На Юге движение за бесплатные общие школы, существовавшие на средства от общего налогообложения, еще не встало на ноги.

«Образованием белых детей - полемизирует судья, - здесь в основном занимались частные группы. Обучение негров практически отсутствовало, и почти все они были неграмотны. По сути дела, любое обучение негров было запрещено законом в некоторых штатах. По сравнению с прошлым веком в настоящее время многие негры добились выдающихся высот в искусстве и науке, предпринимательстве и профессиональном мире».

Действительно, во времена принятия поправки образование в государственных школах было более развито на Севере. Однако вместе с тем влияние, оказываемое Поправкой на северные штаты, в целом игнорировалось в дебатах, проходивших в Конгрессе. Даже на Севере условия государственного образования были весьма далеки от тех, которые существуют в настоящее время.

Как правило, учебная программа была в зачаточном состоянии. В сельской местности существовали школы с общими классами. Во многих штатах учебный семестр длился три месяца, а обязательное посещение школы было практически неизвестно. В результате неудивительно, что в истории применения Поправки XIV столь незначительно ее влияние на государственное образование.

В первых делах, рассматриваемых настоящим Судом, истолковывающим Поправку XIV, Суд разъяснил ее как запрещцющую любые виды дискриминации со сторонь итатов по отночению к негритянской расе.

Доктрина «разных, но равных» возможностей не обсуждалась в настоящем Суде до 1896 г., когда она возникла при рассмотрении дела Plessy v. Ferguson, su- pra, связанного не с образованием, а с доставкой детей в школы. С этого времени американские суды работали с доктриной в течение более полувека.

До настоящего момента Верховный Суд занимался рассмотрением 6 дел, связанных с доктриной «разных, но равных» возможностей в области государственного образование. Так, при рассмотрении дел Comming v. County Board of Education, 175 U.S. 528 u gong Lum v. Rice 275 U.S. 78 не ставилась под вопрос правомерность самой доктрины.

При рассмотрении более поздних дел, все из которых были на уровне средних школ, неравенство было обнаружено в том, что в благах, получаемых белыми учащимися, было отказано негритянским учащимся с одинаковыми образовательными данными. Это были дела Missouri ex. rel. gaines v. Canada, 305 U.S. 337; Sipuel v. Oklahoma, 332 U.S. 631; Sweari v. Painter, 3 W U.S. 624; McLaurin v. Oklahoma State Regents, 339 U..S. 637 - ни в одном из них не пришлось пересматривать доктрину, чтобы удовлетворить иски, представленные негритянскими истцами. А по делу Sweatt v. Painter supra Суд вынес особое мнение относительно применимости дела Plessy v. Ferguson к государственному образованию ${ }^{11}$.

В вышеуказанных делах вопрос поставлен прямо. Здесь в отличие от дела Plessy v. Ferguson coдержатся заключения о том, что соответствующие школы для негров и школы для белых были уравнены или уравниваются в отношении зданий, учебных программ, квалификации и окладов преподавателей и прочих «существенных» факторов. Из этого следует, что заключение Верховного Суда не должно ограничиваться лишь сопоставлением этих существенных факторов в школах для негров и школах для белых, о которых идет речь в каждом из этих дел.

«При рассмотрении этой проблемы, - говорится в деле, - мы не можем обратить время вспять к 1868 г., когда была принята Поправка XIV, или даже к 1896 году, когда было принято решение по делу Plessy v. Ferguson. Мы должны рассмотреть систему государственного образования в свете его полного развития и его современного места в американской жизни по всей стране. Только так можно установить, что сегрегация в государственных шкалах лишает этих истцов равной защиты законов.

${ }_{11}^{11}$ Жиков О.А. Верховный суд США: право и политика. - М., 1985. - C. 103. 


\section{Политика и общество 8 (104) • 2013}

Вероятно, сегодня образование является самой важной функцией органов власти штатов и местных органов власти. Законы об обязательном посещении школы и большие расходы на образование свидетельствуют о нашем признании роли образования в нашем демократическом обществе.

Образование необходимо в отправлении наших коренных обязанностей перед обществом, даже включая службу в вооруженных силах. Оно является самим фундаментом достойного гражданства. Сегодня оно является основным инструментом, позволяющим ребенку воспринимать культурные ценности, подготовиться к получению профессии, а также помогает ему нормально вписаться в окружающую среду.

В наши дни представляется сомнительным, чтобы любой ребенок преуспел в жизни, если он был лишен возможности получать образование. Такая возможность является его правом, которое должно быть предоставлено каждому ребенку, если штат берет на себя ответственность за ее обеспечение.

Мы подходим к поставленному вопросу: лишает ли разделение детей в государственных школах по признаку расы, даже при прочих равных материальных возможностях и других существенных факторах, детей, принадлежащих к национальным меньшинствам, возможностей для получения образования? Мы полагаем, что именно так обстоит дело.

В заключении по делу Sweatt v. Painter о том, что сегрегированная школа правовых наук для негров не может обеспечить им равные возможности в области образования, настоящий Суд в значительной мере полагался на те «качества, которые не поддаются объективной оценке, по которым обеспечивают величие какой-либо школы права».

В деле McLaurin v. Oklahoma State Regents, supra Суд, выдвигая требование о допуске негров в среднюю школу для белых, вновь прибег к использованию нематериальных доводов, таких, как «... его способность учиться, участвовать в дискуссиях и обмениваться мыслями с другими учащимися, а также в целом овладеть своей профессией». Такие соображения с особой силой применимы к учащимся средней школы. Их обособление от других учащихся такого же возраста и обладающих такими же способностями исключительно по признаку расы порождает чувство неполноценности в отношении их положения в обществе, что может отрицательно сказаться на их сердцах и умах, а это уже вряд ли будет возможно исправить в будущем.
О влиянии, оказываемом такой сегрегацией на их возможности получить образование, было хорошо сказано в заключении по канзасскому делу Судом, который, тем не менее, счел себя обязанным вынести решение не в пользу негритянских истцов: «Сегрегация белых и цветных детей в государственных школах оказывает отрицательное влияние на цветных детей. Это влияние возрастает, когда оно санкционировано законом, так как политика разделения рас обычно понималась как подтверждение неполноценности негритянской группы. Чувство неполноценности отрицательно сказывается на стремлении ребенка к учебе. Следовательно, сегрегация, санкционированная законом, имеет тенденцию затормаживать образовательное и умственное развитие негритянских детей, а также лишать их определенных благ, которые они могли бы получить от школьной системы, интегрированной с расовой точки зрения.

Каким бы ни был объем знаний в области психологии в момент слушания дела Plessy v. Feigason, правильность этого заключения подтверждается современными авторитетами ${ }^{12}$. Любая формулировка в деле Plessy v. Ferguson, противоречащая настоящему заключению, отвергается.

На основании вышеизложенного мы делаем вывод о том, что в области государственного образования доктрина "раздельных, но равных возможностей» не имеет места. Раздельные учебные заведения неравны уже по своей природе. Следовательно, мы утверждаем, что истцы и иные лица, оказавшиеся в подобном положении и для защиты которых было возбуждено дело в связи с фактами сегрегации, обжалованными ими, лишены равной защиты по законам, гарантированной Поправкой XIV. Это положение делает излишним любое обсуждение вопроса о том, является ли такая сегрегация также нарушением раздела о надлежащей правовой процедуре, который является составной частью Поправки XIV.

\footnotetext{
${ }^{12}$ Кларк К. Б. Влияние предвзятости и дискриминации на развитие личности. Конференция в Белом доме по проблемам детей и юношества 1950 г.; Уитмер и Котинский. Становление личности 1952 г., гл. Дойтшер и Чейн. Психологические последствия принудительной сегрегации: обзор социологических выводов // Journal of Psychology. - 1948. № 9. vol. 26. - Р. 259; Чейн. Каковы психологические последствии в условиях равных возможностей? // International Journal «Взгляды и отношение». № 19-W. - Р. 229; Брамельд. Расходы на образование в условиях дискриминации и в социальном обеспечении. - Изд-во: Макивер, 1949. - С. 44-48.
} 
Вследствие того, что они представляли собой классовые действия в силу применения настоящего решения, а также вследствие существенных различий в местных условиях формулировка решений в этих делах представляет собой довольно-таки сложную проблему.

В опровержение этого рассмотрение вопроса об оказании существенной помощи было по необходимости подчинено главному вопросу, а именно вопросу о конституиионности сегрегаиии в системе государственного образования.

Настоящим мы заявили, что сегрегация представляет собой отказ в обеспечении равной защиты законов. Для того чтобы мы могли воспользоваться всесторонней помощью сторон при разработке постановлений, рассмотрение дела будет отложено, в то время как сторонам предлагается представить новые доводы по вопросам 4 и 5 , ранее изложенным Судом, для нового обоснования этого Положения ${ }^{13}$.

Снова требуется вмешательство Генерального атторнея США. Генеральным атторнеем штатов, требующим или допускающим сегрегацию в государственной системе образования, будет также разрешено появиться в качестве атісі curiae по требованию, поступившему 15.09.1954 г., что отражено в кратком изложении доводов от 01.10.1954 г.».

Результатом введения в некоторых штатах страны Программы «Student Accountability Programs» стала очередная реакция Верховного суда США при разрешении дела Eric V. v. Johnston County ${ }^{14}$.

Из сути дела следует, что родители и студенты школ школьного округа графства Джонстон были информированы о том, что «студенты, нуждающиеся в помощи при обращении к стандартным тестам на определении уровня знаний, будут определены в начале учебного года, но воспользоваться этой возможностью можно будет в течение года, как только студенты посчитают себя подготовленными для сдачи тестов» ${ }^{15}$.

\footnotetext{
${ }^{13}$ Исходя из того, что было установлено, что сегрегация в государственных школах является нарушением Поправки XI: (a) последует ли принятие приказа, предусматривающего, что в пределах нормального географического распределении школ по округам негритянские дети, начиная с настоящего времени должны приниматься в школы в соответствии с их выбором (б) разрешит ли Суд в осуществление своих правовых полномочий эффективный постепенный переход от существующих систем сегрегации к системе, не базирующейся на расовых различиях.

${ }^{14}$ Aug. 28, 1997 Order, 1997 WL 566626, *1.

${ }^{15}$ Борисоглебский Л. «Новые веяния» в американской школе // Народное образование. - 1964. № 4. - С. 102-104.
}

Однако школьным округом так и не были разработаны методики определения обучающихся с высоким уровнем риска отставания в обучении, и в течение всего года администрация школ применяла совершенно неотработанную и не систематизированную методику определения степени такого риска «на глаз», по сугубому убеждению комиссии, и рекомендации учителей. Так, работая в течение 2 лет, попечительскими советами и самими обучающимися было замечено, что лишь только $1 / 4$ всех обучающихся после сдачи таких тестов были допущены к выпускным экзаменам, и $3 / 4$ этих студентов принадлежали к белой расе. Характерно, что результаты в выпускной школе при сдаче экзаменов, были аналогичными.

Таким образом, стало очевидно, что на протяжении 2 лет в школьном округе проводилась политика, нарушающая требования Поправки XIV Конституции США, а также части VI Закона о гражданских правах 1964 г. Суд отклонил мотивировку истцов и наложил предварительный запрет на рассмотрение дела по существу. Также Суд предостерег, что «федеральные суды не имеют полномочий обязывать местные школьные советы устанавливать стандарты качества обучения» ${ }^{16}$.

\section{Об эмансипации...}

Дело Dothard v. Rawlinson 433 US 321, 97 S. Ct. $2720,53 \boldsymbol{L} . \boldsymbol{E d} .2 d, 7861977$ 2. в изложении Верховного судьи Стюарта звучит следующим образом:

«Истец Диана Ролинсон подала заявление о приеме на работу в Управление исправительных работ штата Алабама на должность тюремной надзирательницы, называемую в Алабаме «исправительный советник». После того как ее заявление было отклонено, она представила настоящий иск - в соответствии с Титулом VII Закона о гражданских правах 1964 г., 78 Статут 253 с поправками Суда США 42, § 2000 и далее (изд. 1970 г. и Приложение V), а также в соответствии п. 42 Суда США, § 1983.

В своем иске она утверждала, что ей было отказано в приеме на работу на основании ее пола, что является нарушением федерального законодательства.

Федеральный окружной суд среднего округа штата Алабама в составе 3 судей решил дело в ее пользу (Mieth v. Dothard)..

Еще до рассмотрения иска Совет по делам исправления штата Алабама принял административное Поло-

\footnotetext{
${ }^{16} \mathrm{http}$ : // www.failtest.org/examart/summer98/k-netst.htm.
} 


\section{Политика и общество 8 (104) • 2013}

жение № 204, устанавливающее критерии для пола в решении вопроса о назначении исправительных советников в учреждения особо строгого режима на должности, где «имеется контакт», то есть на должности, требующие постоянного тесного физического контакта.

Во время обращения с заявлением о приеме на работу в качестве стажера исправительного советника Ролинсон исполнилось 22 г. и она была выпускницей колледжа по специальности «Исправительная психология». Ей было отказано в приеме на работу на том основании, что она весила менее 54 кг., т.е. менее веса, требуемого правилами штата Алабама, также устанавливающим минимальный рост в 160 см.

После отклонения ее заявления по причине веса Ролинсон обратилась с заявлением в Комиссию по обеспечению равных возможностей в области найма и, в конечном счете, получила письмо, подтверждающее ее право обратиться с иском в суд. Затем она представила жалобу в окружной суд от своего имени и от имени других женщин, оказавшихся в подобном положении, в которой оспаривалась правомочность установления минимальных требований в отношении роста и веса, что представляет собой нарушение Титула VII и раздела об обеспечении равной защиты, содержащегося в Поправке XIV.

Истец Диана Ролинсон дело проиграла.

\section{О порядке управления...}

В Соединенных штатах, более чем в Англии или Канаде установлена негласная политика жесткого контроля за порядком распределения средств на нужды образования, их расходованием и выработкой решения на местном уровне.

Министр юстиции США Уоррен Берджер в конце 1990-х гг., выступая в Верховном суде, указал: «В стране существует бесконечный ряд традиций по поводу системы государственного образования которые имеют более глубокие причины существования чем вопросы контроля региональных властей над действиями администраций школ. Местные власти долгое время оказывали существенную поддержку образовательному сообществу, поддерживая систему функционирования государственных школ и качество образовательного процесса ${ }^{17}$. Но не всегда было так: в

${ }^{17}$ Lampe Sch. E. Incremental Reform in the United States // Geo. Washington Journal. - 1998. Vol. 31. - P. 282-283. деле San Antonio Independent School v. Rodrigues 1973 2. Верховный суд практически бросил вызов дотационной системе финансирования образовательной системы и системе пожертвования штата $\mathrm{Texac}^{18}$. Суд обвинил администрацию школьного округа Сан-Антонио в том, что она не в «полной степени соответствующих закону основаниях» облагала семьи обучаемых детей различными податями материального и финансового характера.

Таким образом, был создан прецедент правомерности вмешательства администрации штата в управлении школьными округами, и в частности, контроля за расходованием поступающих на счета школ денежных средств.

А Верховный суд штата Нью-Джерси на основании решения Верховного суда США в $1990 \Gamma^{19}$. вынес предупреждение главе финансовой системы штата о неконституционности применения политики предпочтения в финансировании того или иного школьного округ, отдавая предпочтение экономически благополучным районам, руководствуясь Законом о качестве образования 1990 2. $^{20}$. Данный закон установил в штате 30 школьных округов, присвоив им статус «нуждающихся в специальных дотациях», увеличил уровень получаемых им субсидий за счет сокращения объема финансирования «благополучных районов» ${ }^{21}$.

Итак, можно подвести итого, что более всего Верховный суд США рассматривает дела по вопросам сегрегации и десегрегации обучающихся по признакам расы, вероисповедования, национальной, этнической, социальной принадлежности учеников, распределения финансовых средств на нужды школьных округов ${ }^{22}$.

Парадоксально, что такие инциденты имеют место в образовательных учреждениях государства, заведениях, где люди учатся быть грамотными, социально

\footnotetext{
${ }^{18}$ San Antonio Indep. Sch. Dictr. V. Rodrigues, 411 U.S. 1, 6. 1973. - P. 23-26.

${ }^{19}$ Abbott v. Burke, 575 A. 2d 359, 407-08. - N.J., 1990. P. 56-59.

${ }^{20}$ Comprehensive Education Improvement and Financing Act of 1996. - N.J. Stat. Ann. 18A :7D/1 to 4. - P. 13-15.

${ }^{21}$ N.J. Stat. Ann. 18A:7D/1 to 3. Isajiw, supra note 127, at 249-50.

${ }^{22}$ Ruty $W$. School in an Age of Mass Culture. An exploration selected themes in the history of twentieth century American education. - Englewood. Cliffs. N.J.: Prentice-Hall Inc. - 375 p.; Abernathy G. Civil Liberties Under the Constitution. - Mass.: University of South Carolina Press, 1989. - 652 p.
} 
и физически подготовленными к жизни в обществе, политически лояльными и гуманными, умеющими подвергать высокой и справедливой оценке свои поступки и анализировать чужые. Печально, что ответчиками в таких делах выступают школьные округа, администрации школ, основная цель деятельности которых - просвещать и защищать лиц, нуждающихся в получении знаний, навыков, умений.

\section{Библиография:}

1. Борисоглебский Л. «Новые веяния» в американской школе // Народное образование. - 1964. № 4. - С. 102-104.

2. Жидков О.А. Верховный суд США: право и политика. - М., 1985. - С. 103.

3. Олещук Ю.Ф. Эволюция социальной политики США. - М., 1987. - Сю 34-40.

4. США: государство и социальная политика. К анализу консервативных тенденций 1980-х гг. / Под ред. С.М. Плеханова. - М.: Изд-во «Наука», 1988. -186 c.

5. Фридмен Л. Введение в американское право / Пер с англ. / Под ред. М. Калонтаровой. - М.: Изд-во «Прогресс», «Универе», 1993. - 286 с.

6. Comprehensive Education Improvement and Financing Act of 1996. - N.J. Stat. Ann. 18A :7D/1 to 4. P. 13-15.

7. Churches and State. - 1983. № 5. - P. 16.

8. Jeynes W. School Choice // Cambridge Journal of education. - 2001. № 4. - P. 232-235.

9. Lampe Sch. E. Incremental Reform in the United States // Geo. Washington Journal. - 1998. Vol. 31. - P. 282-283.

10. U. S. New and World Report. - 1982. November 15. - P. 4-5.

11. Ruty W. School in an Age of Mass Culture. An exploration selected themes in the history of twentieth century American education. - Englewood. Cliffs.
N.J.: Prentice-Hall Inc. - 375 p.; Abernathy G. Civil Liberties Under the Constitution. - Mass.: University of South Carolina Press, 1989. - 652 p.

12. San Antonio Indep. Sch. Dictr. V. Rodrigues, 411 U.S. 1, 6. - 1973. - P. 23-26.

13. Time. - 1980. December. - P, 23-26.

14. Wright L. Physical education and moral education, Journal of Philosophy of Education, 21, Moral Character and Civic Education in the Elementary School. - New York, Teachers College Press, 1997. - P. 21-24.

\section{References (transliteration):}

1. Borisoglebskiy L. «Novye veyaniya» v amerikanskoy shkole // Narodnoe obrazovanie. - 1964. № 4. S. 102-104.

2. Zhidkov O.A. Verhovnyy sud SShA: pravo i politika. - M., 1985. - S. 103.

3. Oleschuk Yu.F. Evolyuciya social'noy politiki SShA. - M., 1987. - Syu 34-40.

4. Fridmen L. Vvedenie $\mathrm{v}$ amerikanskoe pravo / Per s angl. / Pod red. M. Kalontarovoy. - M.: Izd-vo «Progress», «Univere», 1993. - $286 \mathrm{~s}$.

5. Jeynes W. School Choice// Cambridge Journal of education. - 2001. № 4. - P. 232-235.

6. Lampe Sch. E. Incremental Reform in the United States // Geo. Washington Journal. - 1998. Vol. 31. - P. 282-283.

7. Ruty W. School in an Age of Mass Culture. An exploration selected themes in the history of twentieth century American education. - Englewood. Cliffs. N.J.: Prentice-Hall Inc. - 375 p.; Abernathy G. Civil Liberties Under the Constitution. - Mass.: University of South Carolina Press, 1989. - 652 p.

8. Wright L. Physical education and moral education, Journal of Philosophy of Education, 21, Moral Character and Civic Education in the Elementary School. New York, Teachers College Press, 1997. - P. 21-24. 